\title{
Latitudinal variation of Pc3-Pc5 geomagnetic pulsation amplitude across the dip equator in central South America
}

\author{
Graziela B. D. Silva, Antonio L. Padilha, and Livia R. Alves \\ Space Geophysics Division, National Institute for Space Research (INPE), São José dos Campos, 12227-010, Brazil
}

Correspondence: Graziela B. D. Silva (graziela.silva@inpe.br, grazybdias@gmail.com)

Received: 14 May 2019 - Discussion started: 13 June 2019

Revised: 10 November 2019 - Accepted: 22 November 2019 - Published: 7 January 2020

\begin{abstract}
In order to clarify the equatorial electrojet effects on ground magnetic pulsations in central South America, we statistically analyzed the amplitude structure of Pc3 and Pc5 pulsations recorded during days considered quiet to moderately disturbed at multiple equatorial stations nearly aligned along the $10^{\circ}$ magnetic meridian. It was observed that Pc3 amplitudes are attenuated around noon at the dip equator for periods shorter than $\sim 35 \mathrm{~s}$. It is proposed that daytime Pc3s are related to MHD (magnetohydrodynamic) compressional wave vertically incident on the ionosphere, with the screening effect induced by enhanced conductivity in the dip equator causing wave attenuation. Daytime Pc5s showed amplitude enhancement at all equatorial stations, which can be explained by the model of waves excited at higher latitudes and propagating equatorward in an Earth-ionosphere waveguide. However, a slight depression in Pc5 amplitude compared to neighboring equatorial stations and a phase lag in relation to an off-equatorial station were detected at the dip equator. This wave amplitude depression in the Pc5 frequency band cannot be explained by the ionospheric waveguide model alone, and we propose that an alternative propagation model that allows ULF (ultra-low-frequency) waves to penetrate directly from the magnetosphere to low latitudes could be operating simultaneously to produce these features at the dip equator. Significant effects of the sunrise terminator on $\mathrm{Pc} 3$ pulsations were also observed at the stations closest to the dip equator. Contrary to what is reported at other longitudes, in central South America the sunrise effect decreases the $D / H$ amplitude ratio. We suggest that these differences may arise from the unique characteristics of this sector, with a strong longitudinal variation in the magnetic declination and precipitation of energetic particles due to the presence of the South Atlantic Magnetic Anomaly (SAMA). The $\mathrm{H}$ -
\end{abstract}

component amplification can be explained by enhancements of the zonal electric field near the magnetic equator driven by F-region neutral winds and waves in the fast-mode of propagation during sunrise.

\section{Introduction}

Magnetic pulsations, or ULF (ultra-low-frequency) waves, contain information that can be used to study different physical processes acting in the Sun-Earth system. They can be generated internally in the magnetosphere by various types of disturbances, such as substorms or instabilities associated with cyclotron resonances or drift-bounce resonances, or externally by disturbances in the magnetopause (McPherron, 2005). Its detection on the ground at very low latitudes shows that a significant portion of the energy of these hydromagnetic waves penetrates deep into the magnetosphere and the plasmasphere. Particularly at these latitudes, since ground-based magnetometers respond mainly to changes in E-region currents, pulsations bring records of equatorial ionosphere disturbances associated with complex electrodynamic changes during magnetospheric energy transfer processes.

It is well known that the very low-latitude region is characterized by high zonal ionospheric conductivity alongside the dip equator. The most obvious effect of this increased conductivity is that in a narrow latitude range, centered on the dip equator, the eastward flow of the dynamo current is intensified during daytime. This enhanced current is known as the equatorial electrojet (EEJ). The effect of the EEJ appears as a significant increase of amplitude in the horizontal component of diurnal quiet-time geomagnetic variations, $\mathrm{Sq}$ 
$(H)$, but also in a wide range of short-period fluctuations, which can be observed within a few degrees of latitude on the ground. In the typical pulsation period band, the observed equatorial enhancement close to local noon is $\sim 2-3$ times larger when compared with off-equatorial stations, with a proposed fast decrease for periods smaller than $20 \mathrm{~s}$ (Sarma and Sastry, 1995; Shinohara et al., 1997; Zanandrea et al., 2004).

The mechanisms involved in the generation, propagation, and amplification of equatorial pulsations have not yet been clearly identified. At very low latitudes, a significant portion of the geomagnetic field lines lies within the ionosphere, and therefore the field line resonance theory that explained numerous observations at middle and high latitudes cannot be applied (Yumoto, 1986). Generally, two models are proposed as the possible mechanisms for the generation and propagation of magnetic pulsations near the ground magnetic equator. In the first model, compressional hydromagnetic waves, which propagate from the magnetosheath across the dayside magnetosphere, arrive vertically at the equatorial ionosphere and are interconnected with magnetic disturbances observed on the ground through the ionosphere. It has been proposed that this mechanism is the main source of Pc3 pulsations at low latitudes (Yumoto and Saito, 1983). In the second model, electric fields driven by Alfvén waves in the high-latitude ionosphere propagate horizontally through the atmosphere to low-latitude regions and the Equator in a waveguide bounded by the conducting ionosphere and the ground (Kikuchi and Araki, 1979). Global observations of Pc5 have been interpreted using this equatorward transmission mechanism of the electric field which originated in the polar region (Trivedi et al., 1997). The first model would produce an attenuation of pulsation amplitude at the dip equator as a result of shielding effects, while the second model would generate equatorial enhancement due to the concentration of ionospheric currents at the magnetic equator (Hughes and Southwood, 1976; Shinohara et al., 1997; Tanaka et al., 2004).

Another remarkable feature of the magnetic field in equatorial latitudes is related to the strong longitudinal gradient of ionospheric conductivity near the solar terminator. This feature changes the patterns of the ionospheric currents and consequently of the geomagnetic field reaching the ground. Several authors have studied these effects in regular and irregular geomagnetic pulsations, particularly for the dawn terminator (Saka et al., 1982; Saka and Alperovich, 1993; Tanaka et al., 2007; Imajo et al., 2016). These studies have shown that one of the most prominent effects observed around dawn at very low latitudes is a change in pulsation polarization, characterized by the increase in the $D / H$ amplitude ratio that appears simultaneously with the enhancement of E-layer ionization at the local sunrise. Saka and Alperovich (1993) interpreted the sudden increase of the $D$-component amplitude as caused by a meridional current focused along the dawn terminator.

Most of these previous results were based on data from a single station (Saka et al., 1982; Saka and Alperovich, 1993) or only two stations, one located near the dip equator and the other outside that region (Sarma and Sastry, 1995). Consequently, a detailed mapping of the latitudinal dependence of the pulsation amplification and polarization characteristics at very low latitudes has not yet been performed. In this paper, the horizontal spatial structure of equatorial Pc3 and Pc5 pulsations is investigated using data acquired by a meridional magnetometer profile in central South America, with five stations around the dip equator (within $\pm 3^{\circ}$ dip latitude) and one station located just outside the equatorial region. In addition, the South American longitude sector presents the unique features of strong longitudinal variation in the magnetic declination and the presence of the South Atlantic Magnetic Anomaly (SAMA), where energetic particle precipitation is observed due to the global minimum intensity of the geomagnetic field. This variation in the magnetic field strength and declination angle affects the electrodynamic processes of the local equatorial ionosphere (Abdu et al., 2005), which may also be reflected in some of the characteristics of the ground magnetic pulsations in this area.

\section{Geomagnetic data}

The influence of the equatorial ionosphere on the amplitude of Pc3 and Pc5 pulsations is derived here using geomagnetic data recorded at six stations roughly aligned along the $10^{\circ}$ magnetic meridian in central South America. A fluxgate magnetometer with a self-calibration time system was installed in each of the stations and provided digital data with accuracy better than $0.5 \mathrm{nT}$ in the geomagnetic components $H, D$, and $Z$ (Tachihara et al., 1996). The signal was recorded with a sampling rate of $3 \mathrm{~s}$, and an upper limit around $0.7 \mathrm{nT} \mathrm{s}^{-1}$ was set to ignore fast and very large variations (noise effects or storm sudden commencements (SSCs)). The clock of the data recording system was automatically calibrated by global radio signals (LF OMEGA; Saka et al., 1996), which kept the time accuracy within $100 \mathrm{~ms}$ during the data acquisition. The stations operated simultaneously from September to November 1994, and their data were previously used in several studies to investigate different characteristics of geomagnetic variations at very low and equatorial latitudes (e.g., Shinohara et al., 1998; Padilha et al., 2003, 2017; Zanandrea et al., 2004; Rastogi et al., 2008).

Figure 1 shows a map of South America with the location of the six geomagnetic stations. The location of the Huancayo station (HUA; to be discussed in the text) is also shown. Relevant information from the geomagnetic field for the period in which the measurements were performed is presented. These include the dip equator and the inclination of $\pm 10^{\circ}$ that delimit the region where the EEJ currents are expected to affect geomagnetic variations recorded on the ground (Padilha et al., 2003). Important aspects of the geomagnetic field in this region are the large magnetic decli- 


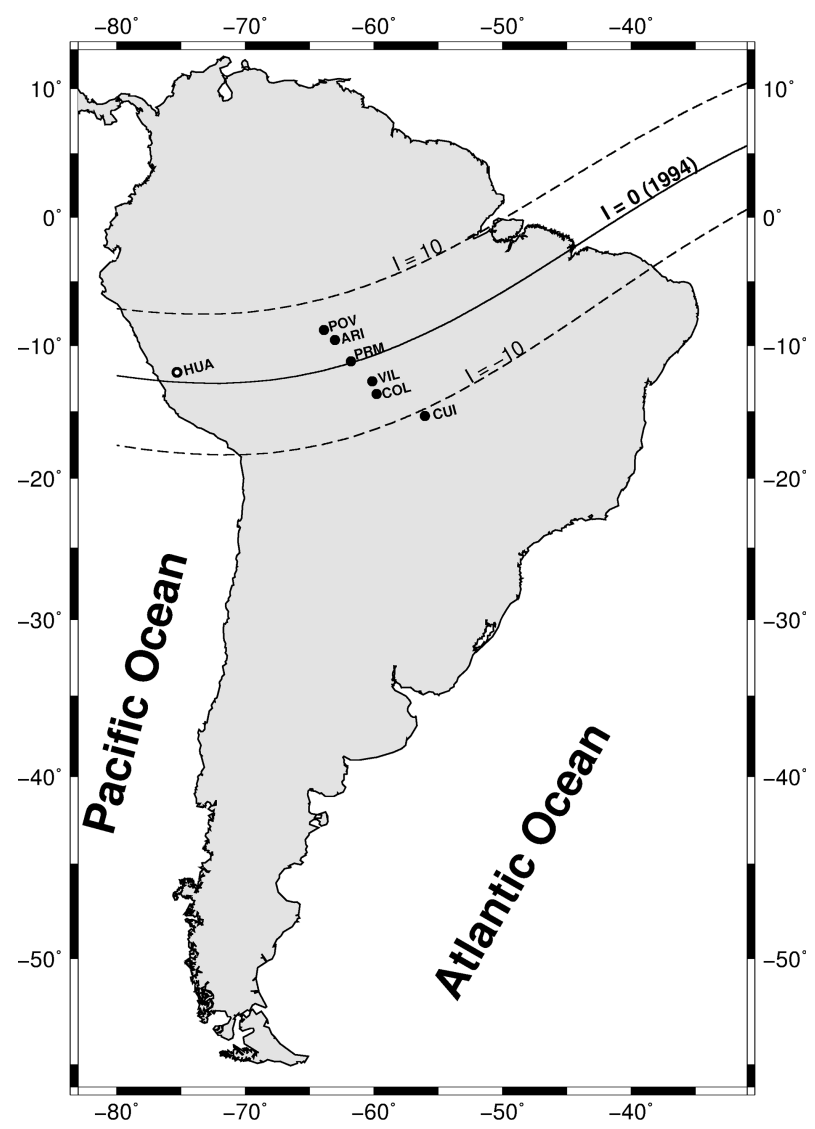

Figure 1. Geographic location of the six geomagnetic stations in South America and contours of the geomagnetic field in 1994. The solid line shows the dip equator $\left(I=0^{\circ}\right)$, and the dashed lines represent $\pm 10^{\circ}$ inclination angles. Location of the Huancayo station (HUA) is also indicated. Geomagnetic field values were obtained from the IGRF model.

nation angle and the associated feature that the dip equator crosses the geographic equator and extends deeper down into the South American continent up to $\sim 12^{\circ} \mathrm{S}$ over the coast of the Pacific Ocean.

Five stations were placed in the equatorial region under the influence of the EEJ currents, with one of them at the dip equator and the other four approximately in conjugate points to the north and south of the Equator. The latitudinal spacings in the equatorial zone are sufficient to obtain a measurable amplitude change, while maintaining a high level of signal coherence between the stations. The other station (CUI) was located immediately outside the EEJ belt and will be used here as a reference to evaluate the EEJ effects on the pulsation events.

All stations were positioned well inland, far away from any ocean or mountain range, but a recent study has shown an extensive anomaly in the underground conductivity beneath the CUI site (Padilha et al., 2017). An amplitude enhancement up to tens of a percent is observed on the ground geomagnetic variations recorded at this station. Using trans- fer functions between two nearby geomagnetic stations, inside and outside the anomaly, these authors established the amplification factors of the geomagnetic field. The amplification varies as a function of frequency due to the reflection of EM (electromagnetic) waves at the interface with the very good conductor and to differences in the damping of the EM wave amplitude during its propagation through the conductive medium inside the Earth. These amplification factors are used here to correct the amplitudes of the geomagnetic variations recorded in CUI.

Geographic and geomagnetic coordinates of the six stations are presented in Table 1. The geomagnetic coordinates refer to the dipole components of the geomagnetic field, whereas the inclination values are derived from the International Geomagnetic Reference Field (IGRF) model. The dip latitude values were calculated from the IGRF inclination values using the formula of Matsushita and Maeda (1965) and will be utilized as a reference for the geomagnetic station location in the final data analysis. The local noon occurs at nearly 16:00 UTC in all stations.

Simultaneous data from the six geomagnetic stations were obtained during $60 \mathrm{~d}$ from 3 September to 1 November 1994. Since we are interested in the ionospheric contribution to Pc3 and Pc5 amplitudes, we preferentially considered the data corresponding to geomagnetically quiet or moderately disturbed conditions. Typical solar daily variations (Sq) in the $H$ component of the geomagnetic fields measured simultaneously by the six stations under quiet solar conditions have already been presented by Padilha et al. (2017). It was observed that the diurnal variation has a maximum around noon $(\sim 16: 00$ UTC), with the largest amplitude at the station closest to the dip equator (PRM) and progressively decreasing to the north and south. The stations at conjugate points (pairs ARI and VIL and POV and COL) have a nearly identical diurnal variation profile.

Figure 2 shows the behavior of the geomagnetic field during the measurement period through geomagnetic indices and the activity level of filtered Pc3 and Pc5 pulsations. The bandpass filter period ranges were 10-45 s (Pc3) and 150$600 \mathrm{~s}$ (Pc5). The Dst (disturbance storm time) index indicates geomagnetically active conditions during this period with the occurrence of one intense (minimum Dst of $-123 \mathrm{nT}$ on 29 October) and three moderate magnetic storms (Dst minima between -50 and $-100 \mathrm{nT}$ on 25 September and 3 and 23 October). The AE (auroral electrojet) index provides a measure of auroral electrojet activity and indicates that, in addition to the disturbed periods during the four magnetic storms, another enhanced substorm activity took place between 6 and 14 September. The variance levels of the $H$ component filtered data in the Pc3 and Pc5 frequency bands of the CUI station are also shown to indicate the level of wave activity. It can be seen that the pulsation activity is concentrated mainly during the disturbed intervals indicated by the $\mathrm{AE}$ index. To minimize the contribution of the nonequatorial ionosphere to the pulsation amplitude, we dis- 
Table 1. Geomagnetic and geographic information of the six geomagnetic stations.

\begin{tabular}{llrr|rrrrr}
\hline Station & Code & \multicolumn{2}{c}{$\begin{array}{c}\text { Geographic } \\
\text { coordinates }\end{array}$} & \multicolumn{2}{c}{$\begin{array}{c}\text { Geomagnetic } \\
\text { coordinates }\end{array}$} & $L$ & $\begin{array}{r}\text { Magnetic } \\
\text { inclination }\end{array}$ & $\begin{array}{r}\text { Dip } \\
\text { latitude }\end{array}$ \\
\cline { 2 - 6 } & & Lat. & Long. & Lat. & Long. & & & \\
\hline Porto Velho & POV & -8.8 & -63.9 & 2.63 & 7.65 & 1.00 & 5.73 & 2.87 \\
Ariquemes & ARI & -9.56 & -63.04 & 1.68 & 8.38 & 1.00 & 3.95 & 1.98 \\
Presidente Médici & PRM & -11.2 & -61.8 & 0.55 & 9.44 & 1.00 & 0.34 & 0.17 \\
Vilhena & VIL & -12.72 & -60.13 & -1.85 & 10.64 & 1.00 & -3.35 & -1.68 \\
Colibri & COL & -13.7 & -59.8 & -2.87 & 10.77 & 1.00 & -5.3 & -2.66 \\
Cuiabá & CUI & -15.35 & -56.05 & -5.64 & 13.89 & 1.01 & -10.76 & -5.43 \\
\hline
\end{tabular}

carded the events during the main phase of the magnetic storms. The temporal location of the chosen events is shown in the AE index graph, which indicates that they are mainly concentrated during the substorm activity and in the recovery phases of the magnetic storms.

\section{Data processing}

\subsection{Selection of Pc3 and Pc5 events}

The time series data were digitally filtered in Pc3 and Pc5 frequency bands using a recursive Butterworth bandpass type, with unit gain within the chosen frequency band (Kanasewich, 1981). Since ground pulsations near the geomagnetic equator are known to be strongly polarized to the $H$ component, we initially searched for simultaneous pulsations events in this component for time intervals representing daytime (14:00-18:00 UTC corresponding to 10:00-14:00 LT) and nighttime (22:00-10:00 UTC corresponding to 18:0006:00 LT). Daytime data allow us to evaluate the influence of the EEJ on the signals, and the time interval around noon is when these currents are more intense (Le Mouel et al., 2006), while nighttime data are used as a reference of signals less affected by the equatorial ionosphere. The hourly variance of the $H$ component in CUI was used to find the relevant events, which were later investigated in the equatorial stations. Figures 3 and 4 show examples of Pc3 and Pc5 events simultaneously observed in all stations.

Visual inspection indicates that the Pc3 pulsation is apparently damped at the PRM station (under the dip equator) compared to the other equatorial stations. On the other hand, the Pc5 pulsation is strongly amplified in all equatorial stations in relation to CUI. In addition, the strong equatorial polarization to the $H$ component is also observed, especially for the Pc5 event. These results agree with those reported previously (e.g., Sarma and Sastry, 1995; Trivedi et al., 1997) and show the strong effect of EEJ currents on pulsation amplitude around local noon.
To emphasize the effect of equatorial ionospheric currents on the pulsation amplitude, we chose days with little magnetic activity in the equatorial region. Only those days where the minimum Dst value was greater than $-50 \mathrm{nT}$ were chosen, thus eliminating the main phase of the four magnetic storms. Under these conditions, $30 \mathrm{~d}$ with significant signals of Pc3 and Pc5 pulsations were found. In these days, $77 \mathrm{Pc} 3$ and 65 Pc5 clear events were identified. Most of the selected Pc3 wave packets have a duration of about $3 \mathrm{~min}$, while Pc5 wave packets lasted less than $24 \mathrm{~min}$.

\subsection{Relative amplitude of equatorial Pc3 and Pc5 pulsations}

Following the procedure described in Roy and Rao (1998), the characteristic period of each event was determined from spectral analysis. In this procedure, a fast Fourier transform (FFT) is applied to intervals of the filtered time series containing the pre-chosen events. An analysis is made to verify that the same major spectral peak is observed simultaneously in all stations, taken as indicative of a coherent pulsation event. The characteristic period of each signal is then defined from this maximum spectral peak. In addition, the CUI station signals were corrected using the period-dependent amplification factors defined by Padilha et al. (2017). The correction factor in the $\mathrm{Pc} 3$ frequency band is given by a 2 nddegree polynomial function, whereas a 4th-degree polynomial function was used for the Pc5 band (pulsations in the CUI station shown in Figs. 3 and 4 were previously corrected for the underground amplification).

Also following Roy and Rao (1998), the EEJ effect for each event was estimated by the ratio between the spectral amplitudes (in units of $\mathrm{nT} / \sqrt{\mathrm{Hz}}$ ) of the equatorial stations and the spectral amplitude at the off-equatorial station (CUI). Thus, ratios (or relative amplitudes) greater than one correspond to equatorial amplification, whereas ratios smaller than one indicate equatorial damping. Figure 5 exemplifies the procedure for the Pc3 event shown in Fig. 3. The left panels (a-f) show the dynamic spectrograms of the Pc3 event for each geomagnetic station, where $0 \mathrm{~dB}$ corresponds to $1 \mathrm{nT}^{2} \mathrm{~Hz}^{-1}$. These power spectral density (PSD) 


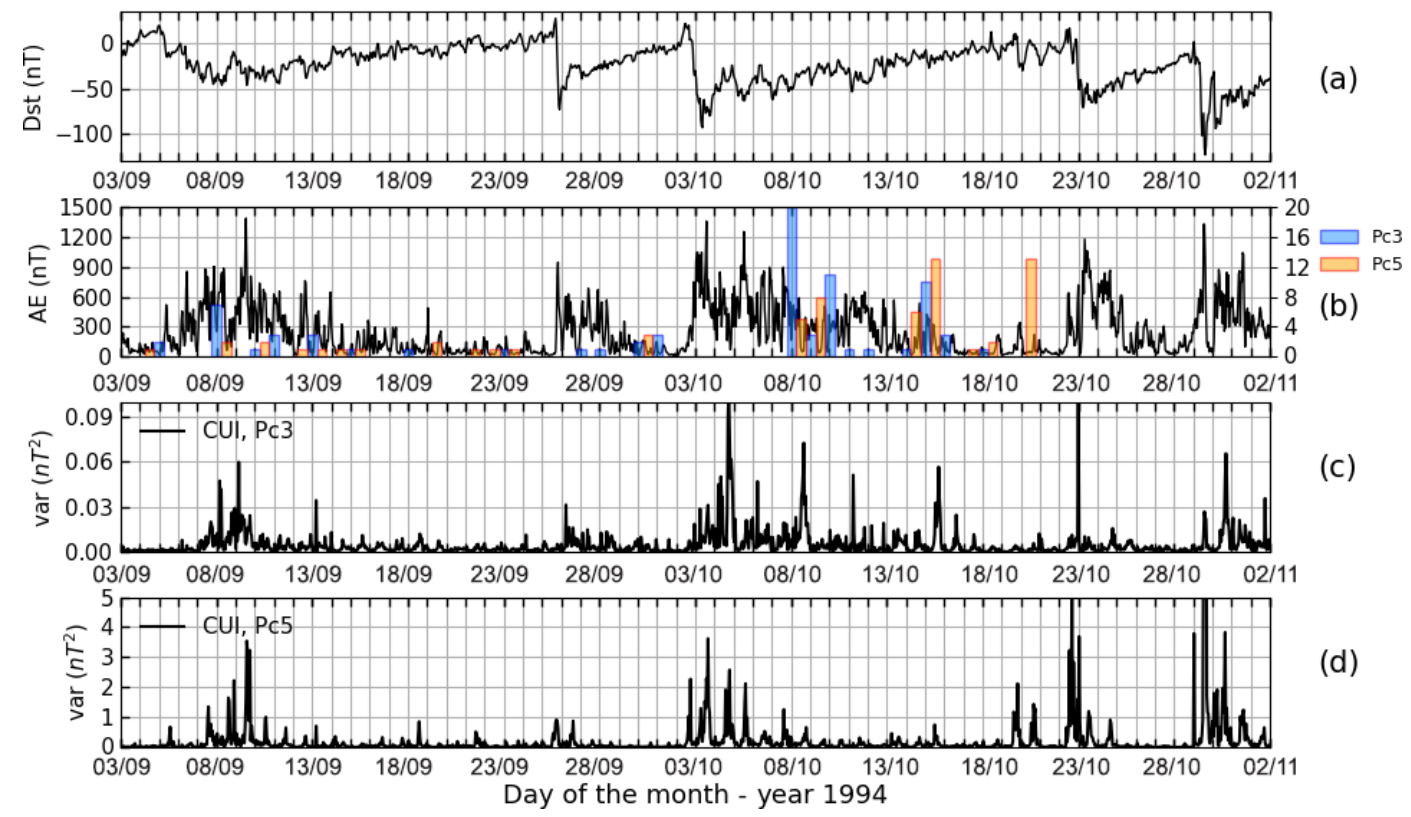

Figure 2. Geomagnetic indices and filtered ground geomagnetic pulsations during the period from 3 September to 1 November 1994. (a) Dst index; (b) AE index with the temporal location and number of events chosen for the pulsation analysis; (c) variance of Pc3 pulsations in the $H$ component of the CUI station; (d) variance of Pc5 pulsations in the $H$ component of the CUI station.
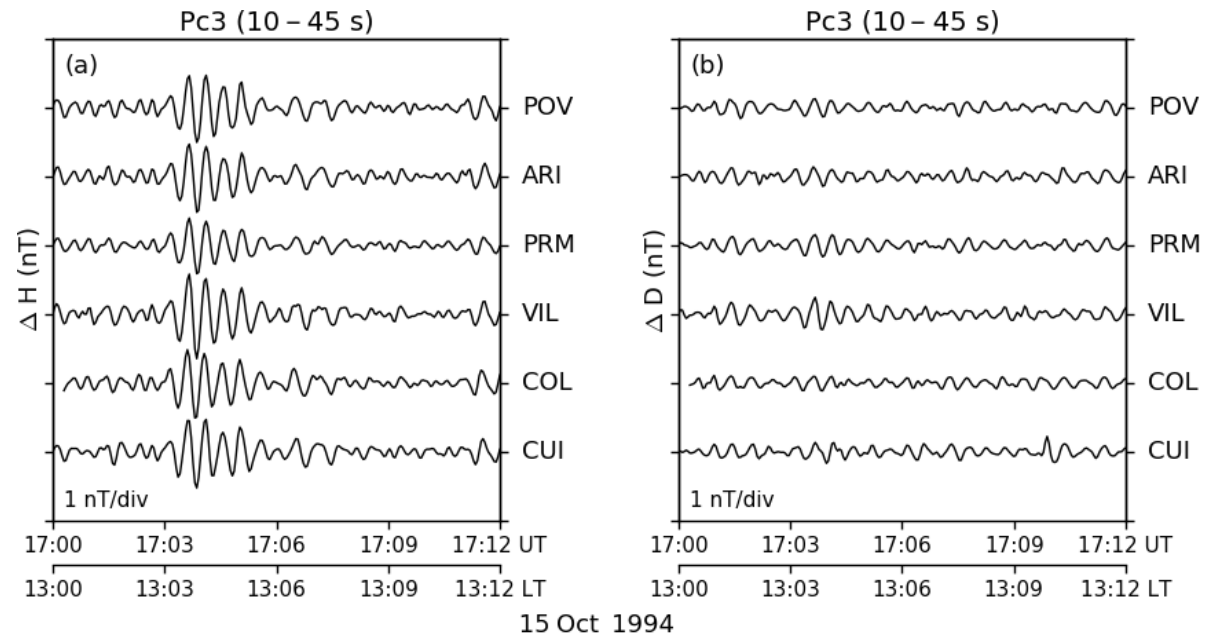

Figure 3. Band-pass-filtered geomagnetic variations ( $H$ and $D$ components) in the Pc3 interval (10-45 s), shortly after noon on 15 October 1994. A Pc3 event starting at $\sim$ 13:03 LT is observed.

distributions have the same trend identified visually in the time series of Fig. 3, with the PRM signal substantially attenuated in comparison with the other stations. It can also be noted that the VIL station has greater amplitude for this event, while the other stations have similar PSD values. The average spectral amplitude for this event at each station is shown on the right (panel g), where the period of peak amplitude in CUI is identified. This period is used as a reference to obtain the spectral amplitude of all stations. The ratios between the spectral amplitudes of the other stations and the spectral amplitude in CUI are then calculated to derive an amplification (or damping) factor for each equatorial station for that specific event.

Figure 6 shows the occurrence distribution of Pc3 and Pc5 relative amplitudes for all events at each equatorial station as a function of local time (LT) and universal time (UTC). It can be seen that most of the Pc3 events are slightly amplified in the equatorial region, during both daytime and nighttime. However, there is a larger number of damped events around noon. This is particularly salient for the dip equator (PRM station), where most of the events are significantly damped. An increase in the Pc3 amplification is observed in 

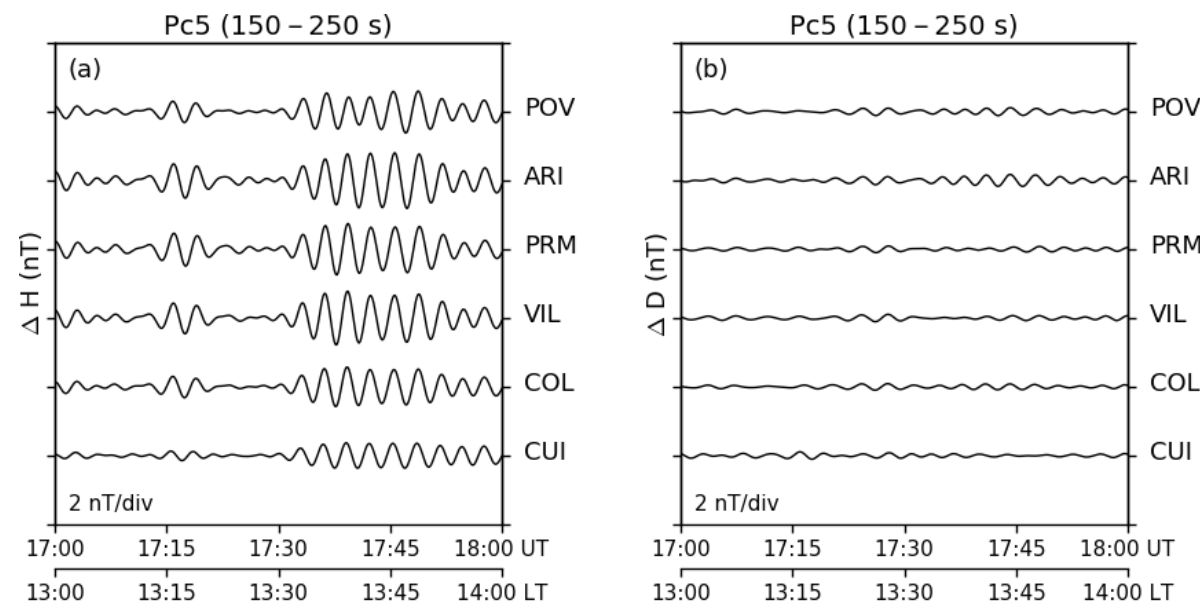

15 Oct 1994

Figure 4. The same as Fig. 3, for Pc5 pulsations with periods ranging from 150 to $250 \mathrm{~s}$, in the afternoon on 15 October 1994 . An event is observed in the $H$ component after 13:30 LT.
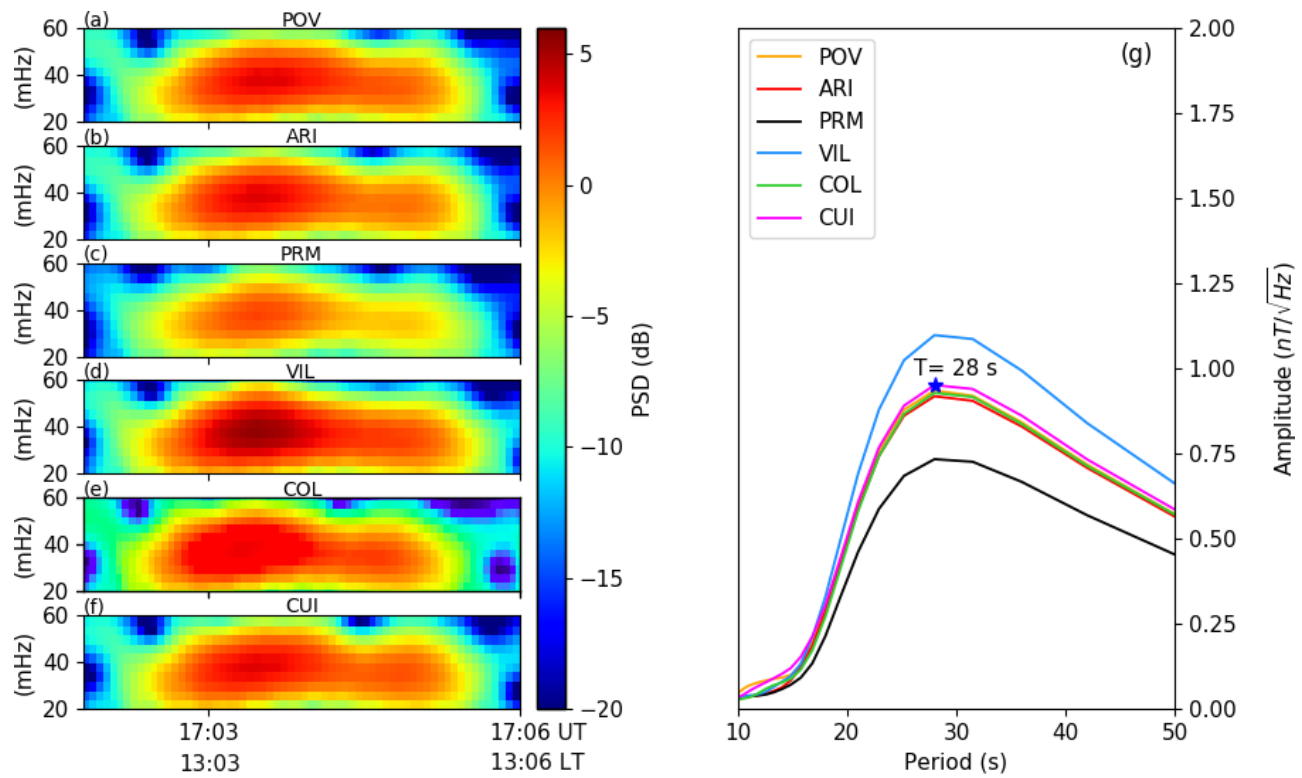

Figure 5. Power spectral analysis for the Pc3 pulsation on 15 October 1994 shown in Fig. 3. Left panels (a-f) show dynamic spectrograms of power spectral density during the event. Right panel (g) shows the average spectral amplitude at each station with identification of the period of peak amplitude in the CUI station.

stations POV, ARI, PRM, and VIL shortly before 06:00 LT. This amplification is associated with the sunrise effect and will be discussed later in greater detail. On the other hand, almost all Pc5 events are amplified at equatorial stations. The highest amplifications are observed during daytime (06:00 to 18:00 LT) in all stations.

The relative amplitudes of the Pc3 pulsations were also analyzed as a function of the wave period. For this analysis we used only nighttime events (18:00 to 06:00 LT) and noon events (10:00 to 14:00 LT). It can be observed in Fig. 7 that nighttime events are not dependent on the period, be- ing preferably amplified throughout the Pc3 band. On the other hand, the noon events present significant differences as a function of the period. It should be noted that, in the latter case, no pulsations with a period shorter than $27 \mathrm{~s}$ were observed. Besides, there is an evident cutoff period around $35 \mathrm{~s}$ for amplification or damping under the dip equator. Events with periods shorter than $35 \mathrm{~s}$ are damped, while longer periods are amplified. This observation explains why some events around noon in Fig. 6 show amplification at the PRM station (these events have periods longer than $35 \mathrm{~s}$ ). In summary, these results show that at the dip equator there is 

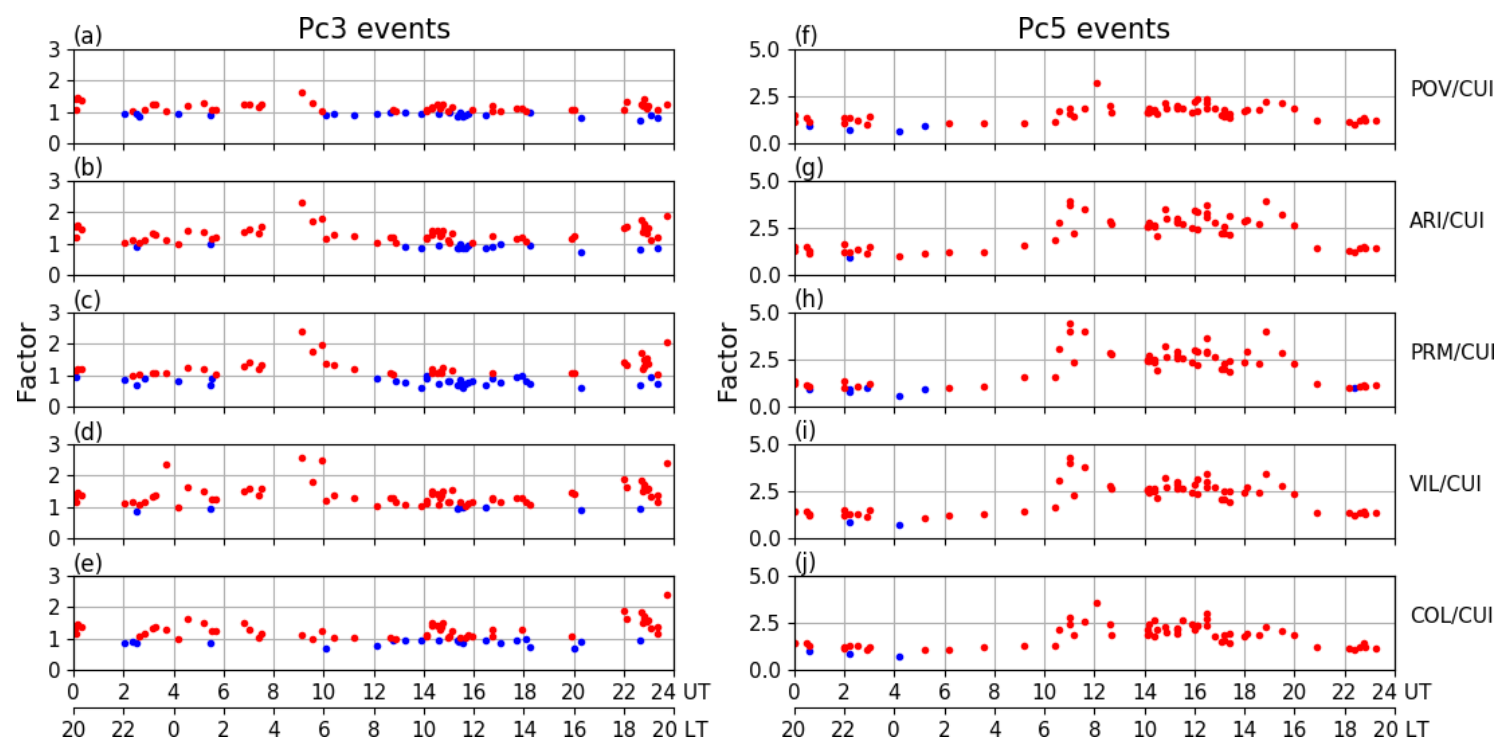

Figure 6. Local time dependence of occurrence distributions of Pc3 and Pc5 relative amplitudes at the equatorial stations. In red are values greater than one (amplification); in blue are values less than one (damping).

an amplitude damping in Pc3 pulsations with periods of less than $35 \mathrm{~s}$, when EEJ currents are well developed around local noon.

\section{EEJ effects on pulsation amplitude}

We found that Pc3 amplitudes undergo a depression under the dip equator around noon, and this is a period-dependent phenomenon. On the other hand, Pc5 amplitudes are enhanced at all equatorial latitudes, regardless of the period. During nighttime, Pc3 and Pc5 amplitudes are slightly increased for all stations in the equatorial region. These results from the central South American region agree with many previous studies at similar latitudes, based on both ground observations and theoretical models of excitation and propagation of MHD (magnetohydrodynamic) waves that lead to pulsation activity on the Earth's equatorial surface (e.g., Yumoto et al., 1985; Itonaga and Kitamura, 1993; Roy and Rao, 1998; Takla et al., 2011). However, they contradict other studies that showed daytime Pc3 amplification in the equatorial region, without specifying any damping interval (Matsuoka et al., 1997; Zanandrea et al., 2004).

Our results can be explained by considering the mechanisms for the generation and propagation of the magnetic pulsations until their detection on the ground at the equatorial region. As discussed by Yumoto (1986), two models have been proposed to explain Pc3 waves observed at very low latitudes. In the first model, upstream waves generated by ion-cyclotron instabilities on the bow shock propagate in the form of compressional waves along the equatorial plane of the magnetosphere, cross the lines of the magnetic field, and arrive directly at the equatorial ionosphere. In the sec- ond model, surface waves generated by instabilities at the diurnal magnetosphere boundary (such as Kelvin-Helmholtz instabilities) propagate to the high-latitude ionosphere and generate large-scale ionospheric current oscillations at these latitudes. These high-latitude currents leak into low latitudes and can cause Pc3 pulsations near the magnetic equator. Following Yumoto (1986), the latter model cannot explain the occurrence of equatorial Pc3 because they can only be transmitted to the high-latitude ionosphere due to the high damping of these waves in their propagation in the radial direction. Therefore, equatorial Pc3 pulsations are more likely to be related to the direct transmission of the compressional fast mode towards the ground. These waves are usually controlled by the solar wind parameters and the interplanetary magnetic field (IMF), with their transmission into the Earth's magnetosphere connected to small cone angle values (Russell et al., 1983).

Theoretical considerations about variations on pulsation amplitude due to the direct incidence of a plane compressional MHD wave on the equatorial ionosphere were obtained in different studies (e.g., Itonaga and Kitamura, 1993; Itonaga et al., 1998). These models predict a depression in the amplitude of the pulsation on the ground at the dip equator, since the induced ionospheric currents act as an obstacle in the propagation of compression waves. Such depression arises from the ionospheric screening effect which becomes more marked as the ionospheric conductivity increases. Consequently, these models predict a greater damping in the pulsation amplitude at the dip equator around noon (when the ionospheric conductivity reaches its maximum), as observed in our data. On the other hand, although some of these models take into account the frequency dependence for this pulsa- 

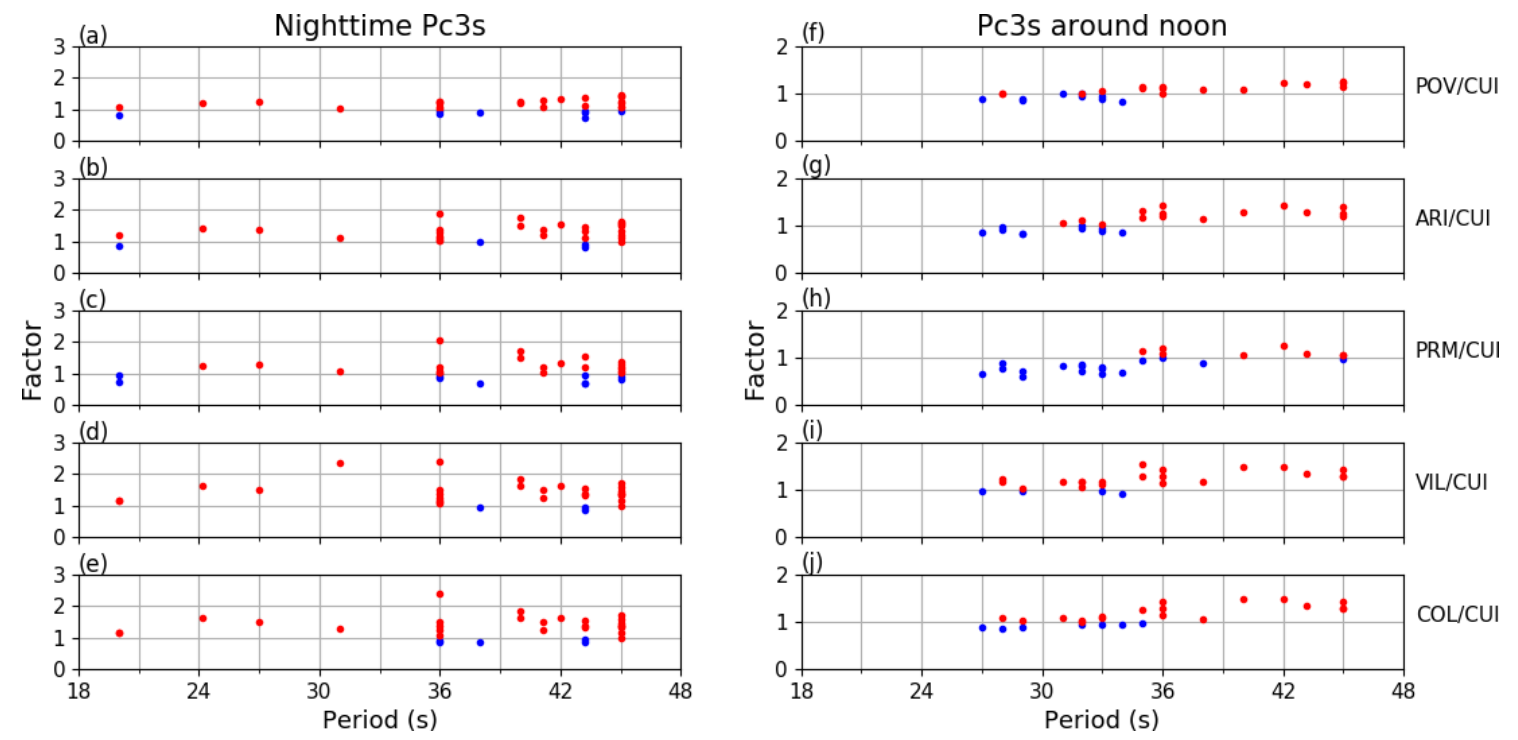

Figure 7. Period dependence of the relative amplitudes of nighttime and noon Pc3 pulsations in equatorial stations.

tion amplitude depression under the dip equator, there is still no clear physical explanation for the occurrence of a maximum period that limits this damping effect.

Pc5 waves are a persistent component of a disturbed magnetosphere, and their possible sources include KelvinHelmholtz oscillations in the magnetopause, the excitation of cavity or waveguide modes, the direct control by oscillations in the solar wind, the fluctuation of field-aligned currents in the auroral zone, and drift-bounce resonance with ring current particles (Hughes, 1994; Elkington, 2006; Kessel, 2008). They are often observed near auroral latitudes, but they can also be observed at middle and low latitudes (Ziesolleck and Chamalaun, 1993). The occurrence of these waves at equatorial latitudes (Reddy et al., 1994; Trivedi et al., 1997) led to the proposition of different penetration mechanisms. Kikuchi and Araki (1979) argued that the ULF wave energy arrives at high latitudes first from the magnetosphere and then propagates to low latitudes through an ionosphere waveguide, while Chi et al. (2001) proposed a combination of fast and shear Alfvén waves which allow ULF waves to penetrate low latitudes directly from the magnetosphere.

The Earth-ionosphere waveguide model of Kikuchi and Araki (1979) was initially developed to elucidate the simultaneous observation of the preliminary reverse impulse (PRI) of the magnetic sudden commencement (SC) at high latitudes and at the magnetic dip equator. It was later expanded to explain the equatorial enhancement of a class of shortperiod fluctuations, including Pc5 pulsations. In this model, surface waves generated by instabilities at the dayside highlatitude magnetosphere boundary generate large-scale ionospheric current oscillations at the polar ionosphere. These Pc5-related polar electric fields can propagate to the lowlatitude ionosphere at the speed of light through the zeroth- order transverse magnetic (TM0) Earth-ionosphere waveguide mode and can generate zonal ionospheric currents at low latitudes. A numerical simulation by Tsunomura and Araki (1984) has shown that the amplitude of the polar electric field decreases as it propagates towards the Equator due to the small proportion of the size of the polar electric field in relation to the propagation distance. Nevertheless, the process is still efficient enough to allow the polar waves to reach the dip equator and be abruptly amplified by the high ionospheric Cowling conductivity in that region. Thus, this model predicts an enhancement of Pc5 amplitudes in the vicinity of the dip equator.

Using a global network of magnetometers with high time accuracy, Chi et al. (2001) observed differences in the arrival time of PRI signals at middle and low latitudes. This result raised questions about the validity of the Earth-ionosphere waveguide propagation model of Kikuchi and Araki (1979), which predicts that the PRI onset should be seen simultaneously at all locations on the Earth's surface (for a more complete review of the public discussion between these authors, the reader is referred to Kikuchi and Araki, 2002, and Chi et al., 2002). Chi et al. (2001) suggested that these differences could be explained by MHD wave propagation along the path proposed by Tamao (1964), in which a compressional wave propagates along the Equator until it is converted into a shear Alfvén wave that then propagates along the field lines to the ionosphere. This penetration mechanism has also been recently proposed for different ULF waves (e.g., Yizengaw et al., 2013). Due to the screening effect of the enhanced ionospheric conductivity at the Equator on an MHD wave signal incident from the magnetosphere, this model would lead to a damping of the wave amplitude at the dip equator and a phase lag of this signal compared to an off-equatorial region. 


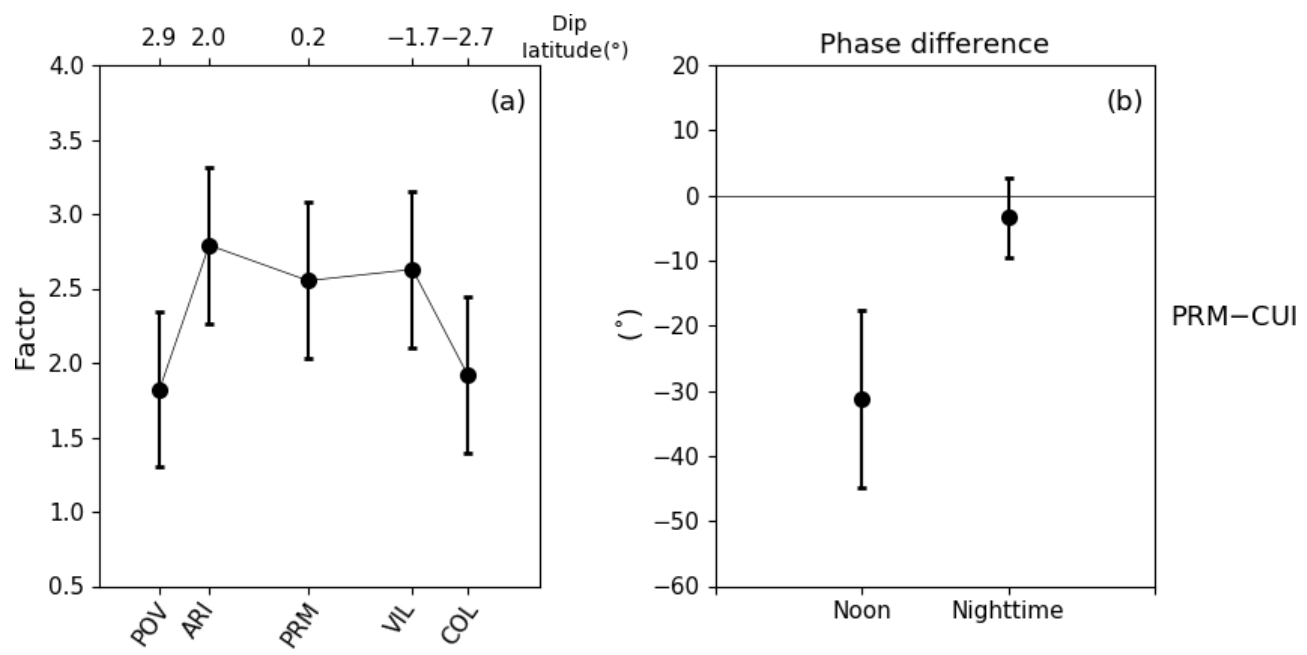

Figure 8. (a) Latitudinal profile of amplification factors for Pc5 pulsations around noon. (b) Phase delays between the dip equator station (PRM) and off-equatorial station (CUI) for Pc5 events during nighttime and around noon. Mean and standard deviations are indicated by dots and bars, respectively.

Both characteristics were tested in our data set. Figure $8 \mathrm{a}$ shows the mean relative amplitudes of Pc5 pulsations around noon for the five stations in the equatorial region, with standard deviation error depicted by error bars. Although the $1 \sigma$ error bars overlap in the different stations, the three stations closest to the dip equator are more amplified, with the lowest amplification observed at the station closest to the dip equator (PRM). This is a statistically robust result, since it represents a tendency observed in $85 \%$ of the events. On the other hand, Fig. $8 \mathrm{~b}$ shows the phase delays between the dip equator station (PRM) and the off-equatorial station (CUI) for Pc5 pulsations recorded during nighttime and around noon. Phase differences for daytime Pc5 have a scattered distribution, ranging from $\sim-45$ to $-20^{\circ}$ and indicating a significant phase delay of the equatorial station relative to the off-equatorial station. This result is in agreement with previous studies in the Brazilian equatorial region (e.g., Shinohara et al., 1998). The nighttime events show less significant phase differences, on average very close to zero. This result is consistent with the absence of significant effects generated by the nighttime equatorial ionosphere. The same model of vertically incident MHD waves used to explain the damping of Pc3 pulsations by the enhanced ionospheric conductivity around noon in the dip equator can also be used to explain the lower amplitude amplification and maximum phase delay observed for Pc5 pulsations. In this latter case, it should be noted that the model of horizontal transmission also allows waves in this mode of propagation to present phase delays at the dip equator. This feature was extensively investigated by Shinohara et al. (1998), who concluded that the induction effect by the equatorial enhanced ionospheric current above the good conductor, Earth, is the main cause of these signal delays.
Generally, the detailed characteristics of the Pc5 amplification and phase delay in the South American equatorial region are not consistent with only one of the proposed wave transmission mechanisms. The Earth-ionosphere waveguide propagation model agrees well with the overall equatorial enhancement and phase delays of these pulsations, but it is inconsistent with the lower amplification observed at the dip equator reported in the study. On the other hand, the MHD wave propagation model explains the local damping in Pc5 amplitudes as well as the expressive phase lag at the dip equator, but it does not account for the general equatorial enhancement of the Pc5 signals. Probably, when the two mechanisms work in an interactive coupled manner, they may explain the variability of the equatorial enhancement. A more advanced theoretical model is needed, which would consider the simultaneous effects from MHD wave propagation and from the Earth-ionosphere waveguide. It must be also considered that fine-scale amplification factors in the equatorial zone should be taken cautiously since ground-based magnetometers have poor spatial resolution because the pulsation signal arises from the effect of ionospheric currents integrated over a transverse ionospheric region of dimensions comparable with the height of the ionosphere (Engebretson et al., 1995).

\section{The sunrise effect}

The local time distribution of Pc3 relative amplitudes in Fig. 6 shows expressive amplification around sunrise at the stations closest to the dip equator (ARI, PRM, and VIL). As an example of such events, Fig. 9 shows band-pass filtered data (10 to $45 \mathrm{~s}$ ) of geomagnetic $H$ and $D$ components during the interval from 07:00 to 07:12 LT on 15 Octo- 
ber 1994. At variance with the Pc3 events around noon (see Fig. 3), this event presents an apparent amplification in the $H$ component at these three stations when compared to the CUI reference station. The pulsations in the $D$ component at all stations are very small so that the almost linearly polarized ellipses in the equatorial belt are predominantly oriented in the north-south direction. Consequently, contrary to previously reported studies at other longitudes, in the central South American equatorial region our data show that the sunrise effect on Pc3 pulsations decreases the $D / H$ (east-west to north-south) amplitude ratio.

Figure 6 presents a small number of events around sunrise. To clarify the significance and effect of the sunrise terminator on Pc3 pulsations, the data were reevaluated to obtain statistically more robust results. Only two stations were used to detect coherent events, one under the dip equator and affected by the dawn effect (PRM) and the other unaffected by this effect (CUI). Using these stations, 32 events were detected between 02:00 and 10:00 LT, and their relative amplitudes (PRM/CUI) are shown in Fig. 10. In this figure, squares are relative amplitudes considering the spectral amplitudes of the $H$ component in both stations, while stars show the relative amplitudes between the $D$ component of the PRM station and the $H$ component of the CUI station. The ratios for the $H$ component are indicative of amplification (ratios greater than one) or damping (ratios less than one) of wave amplitude in the equatorial region, since pulsations are highly polarized in this component at these latitudes. On the other hand, the ratios between the $D$ component in the equatorial region and $H$ component in the off-equatorial region can be used as an indication of a change in wave polarization. It can be seen that most of the events were amplified at the station closest to the dip equator, with the largest amplification occurring around sunrise ( 05:00-06:00 LT). Meanwhile, $D / H$ ratios show values below 0.5 for all events, which can be taken as indicating that no significant change in pulsation polarization occurs under the dip equator.

The amplification characteristics observed by our data are certainly related to the strong longitudinal gradient of the ionospheric conductivity near the dawn terminator. This feature changes the patterns of the ionospheric currents and consequently of the magnetic field on the ground driven by these currents. Considering the strong north-south polarization of the ground pulsations, we suggest that an increase of zonal (east-west) ionospheric currents in the sunlit region adjacent to the dawn terminator controls the observed amplification of the $H$ component. This interpretation is exactly opposite to that commonly proposed as the sunrise effect in other studies, which suggests an increase in the meridional component of the ionospheric currents around the dawn terminator. In particular, this result contradicts that of Saka and Alperovich (1993) at the Huancayo station on the South American west coast, very close to the region of our studies (see location in Fig. 1). However, in agreement with our results, a number of studies based mainly on satellite observations have reported anomalous enhancements of eastward electric fields near sunrise in the equatorial ionosphere, seasonally correlated with the sign of the magnetic declination at the point of observation (Aggson et al., 1995; Kelley et al., 2014; Zhang et al., 2015).

An explanation for this difference can be sought in terms of the existence of large longitudinal variations in electrodynamic processes in the South American equatorial ionosphere, as verified by various types of ground- and satellitebased observations. These variations were reviewed by Abdu et al. (2005) and are associated with the strong longitudinal variation in the geomagnetic declination angle and total field intensity due to the presence of the SAMA. The magnetic declination angle controls the development of the Flayer dynamo in dawn and dusk hours that couples the $\mathrm{E}$ and $F$ regions and plays a key role in the electrodynamics of the equatorial ionosphere. The enhanced ionization by energetic particle precipitation increases the background conductivity distribution in the ionosphere over the SAMA central region and may also extend for several degrees in longitude and latitude, reaching the equatorial ionosphere, even in quiet conditions. The combination of both effects is a unique feature of the South American region and causes significant longitudinal/seasonal differences in the equatorial plasma density distribution.

The dissimilarities in the results between central South America (PRM station) and western South America (HUA station) may therefore arise mainly from differences in the geomagnetic parameters of the two stations. During the experiment of Saka and Alperovich (1993), the magnetic declination angle and the total field intensity in HUA were $1.5^{\circ} \mathrm{E}$ and $27000 \mathrm{nT}$, respectively, whereas during our measurements these values in PRM were $10.3^{\circ} \mathrm{W}$ and $25200 \mathrm{nT}$. This shows that the PRM station is much closer to the central region of the SAMA. In this region, azimuthally drifting energetic particles trapped in the Earth's Van Allen internal radiation belt approach the Earth's surface due to the low values of geomagnetic field intensity, interacting with the dense atmosphere and producing enhanced ionization at ionospheric E layer heights (see, for example, Paulikas, 1975, for a review).

Following Abdu et al. (2005), the extra ionization at PRM due to the SAMA develops polarized electric fields in the vicinity of the enhanced conductivity gradient of the dawn terminator, particularly when external electromagnetic fields (e.g., geomagnetic pulsations) are imposed. A secondary longitudinal electric field structure is produced, which is superimposed, in phase, on the regular zonal electric field. This enhancement of the zonal electric field around dawn can be explained in part following the same mechanism proposed by Farley et al. (1986) for the development of pre-reversal electric field enhancement in the evening hours. In this case, F-region thermospheric winds blowing eastward through the sunrise terminator are the source of sunrise enhancement. Figure 11 illustrates the creation of the polarization electric 

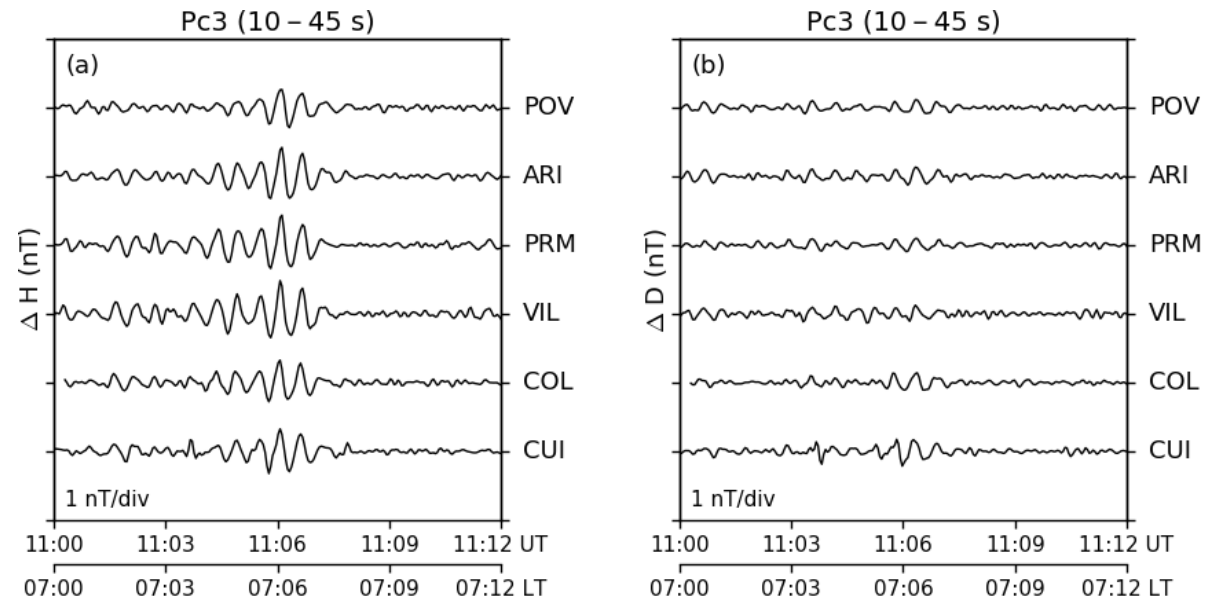

15 Oct 1994

Figure 9. Band-pass-filtered geomagnetic variations ( $H$ and $D$ components) in the Pc3 interval, shortly after sunrise on 15 October 1994.

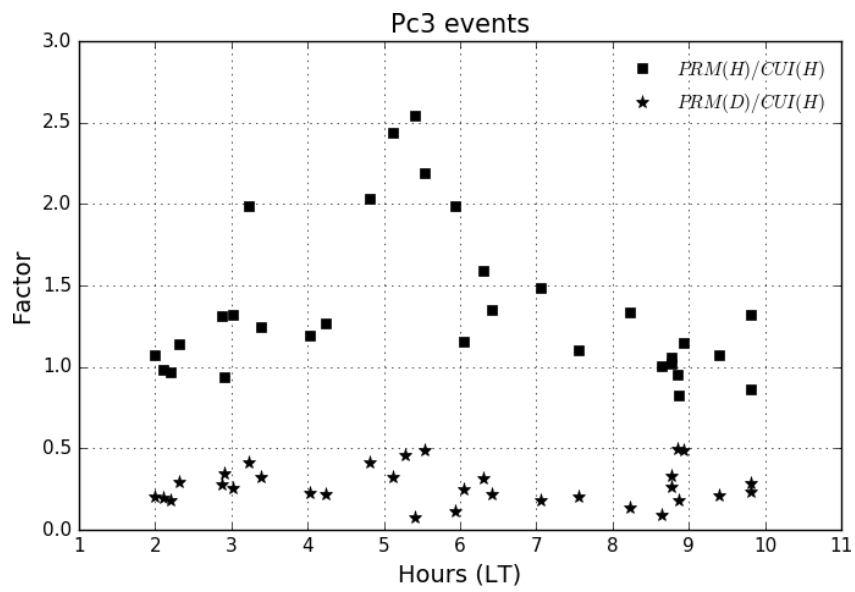

Figure 10. Distribution of Pc3 relative amplitudes between the PRM and CUI stations around sunrise. Squares are ratios of the $H$ component between both stations (PRM/CUI), and stars are ratios between the $D$ component of PRM and $H$ component of CUI.

field in the equatorial $\mathrm{F}$ region and its mapping to the lowlatitude E region (as presented by Kelley et al., 2014). The zonal gradient of the Hall conductance generates an accumulation of positive charges across the sunrise terminator, and, as a consequence, an enhancement of zonal electric fields is developed to the east (dayside) of the terminator.

In addition to this dynamo action, it is known that compressional MHD waves propagating near the solar terminator are also expected to induce zonal ionospheric currents in the vicinity of the dip equator (Saka and Alperovich, 1993). Moreover, according to the model of fast-mode incidence on the ionosphere described by Alperovich and Fedorov (2007), these zonal currents induced by the compressional waves are frequency dependent, with higher frequencies creating strong ionospheric currents and consequently more amplified mag-

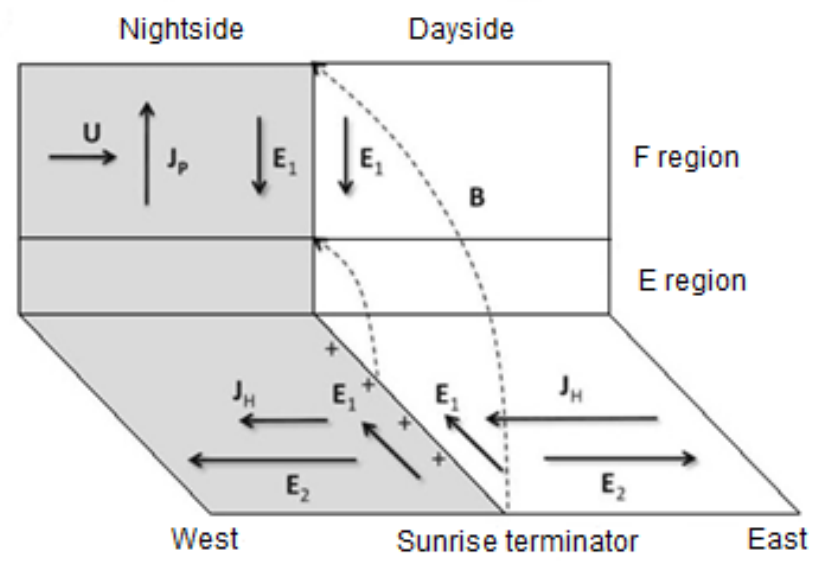

Figure 11. Sketch illustrating the processes responsible for the enhancement of zonal electric fields around sunrise (partially modified from Farley et al., 1986; Kelley et al., 2014). Neutral thermospheric winds $(U)$ moving eastward in the $\mathrm{F}$ region across the dawn terminator give rise to Pedersen currents $\left(J_{\mathrm{P}}\right)$ in the F region, which create the polarization field $\left(E_{1}\right)$ that is mapped to the $\mathrm{E}$ region through the magnetic field lines $(B)$. Hall currents $\left(J_{\mathrm{H}}\right)$ through the terminator create an accumulation of positive charges along the terminator and a secondary electric field $\left(E_{2}\right)$, directed to the east on the dayside and to the west on the nightside.

netic fields on the ground. These same authors also presented experimental evidence that the polarization of pulsations in the Pc3 frequency band is not sensitive to the presence of the terminator during the equinoxes. This is consistent with our results and the period of our measurements (SeptemberOctober). Thus, assuming that our Pc3 pulsations occurring around sunrise are also related to compressional waves vertically incident on the ionosphere (as recognized for the noon events), we can explain their ground amplification and no change in polarization. This is probably due to the net ef- 
fect of zonal currents generated mainly by the electric field carried by the fast-mode waves, substantially enhanced by the secondary longitudinal electric field structure related to the dynamo action through the F-layer thermospheric winds. These effects may also be controlled by the large longitudinal variations of electrodynamic processes in the South American equatorial ionosphere.

The enhancement of the integrated zonal electric field related to the proposed dynamo mechanism attains its largest values when the sunrise terminator is aligned with the magnetic meridian. In central South America, this condition prevails during a period close to the December solstice, when there is a seasonal maximum in the intensity of the secondary zonal electric fields associated with the negative magnetic declination (Zhang et al., 2015). This corresponds exactly to the period in which our measurements were taken. On the other hand, the proposed dynamo mechanism for the zonal electric field enhancement over PRM around sunrise would be seasonally dependent on the solar zenith angle. Due to the limited temporal coverage of our ground measurements, we cannot test this hypothesis at PRM, but Saka and Alperovich (1993) reported a seasonal modulation in the polarization parameters at HUA as a function of the solar angle. Also, despite a large amount of evidence of the longitudinal ionospheric variability in the South American equatorial sector, it is difficult to verify our proposition to explain the observed differences between PRM and HUA due to the lack of direct and simultaneous measurements of ionospheric electric fields at these places.

\section{Summary and conclusions}

Using multipoint observations at equatorial ground stations in central South America, we studied the spatial variation in the amplitude of continuous pulsations (Pc3 and Pc5) observed in the zone of influence of the EEJ currents. Nighttime events in the equatorial region exhibit a systematic pattern of minor amplification, while pulsation amplitude changes during daytime as a function of the period and as the stations approach the dip equator. These results can be explained by the low intensity of the equatorial ionospheric currents at night and by the development of a high ionospheric conductivity along the dip equator during daytime.

We found attenuation in the Pc3 amplitudes around local noon. This amplitude damping is observed exclusively at the station closest to the dip equator and for wave periods shorter than $\sim 35 \mathrm{~s}$. According to previous results and proposed models of excitation and propagation, the main source of equatorial Pc3 must be related to compressional upstream waves, with the amplitude attenuation associated with ionospheric shielding effects (Yumoto et al., 1985). However, the physical concept behind the occurrence of a maximum period limiting the damping effect remains to be elucidated. On the other hand, Pc5 amplitudes show an enhancement at all equa- torial stations, which can be explained by the model of Pc5 waves excited at higher latitudes and propagating equatorward in an Earth-ionosphere waveguide (Kikuchi and Araki, 1979). However, the availability of several stations operating simultaneously under the EEJ currents allowed for the detection of a slight depression in the Pc5 amplitude at the dip equator when compared to neighboring stations (within $\pm 2^{\circ}$ of dip latitude). Also, a phase lag between the Pc5 signals observed at the dip equator and just outside the equatorial region was observed. The former feature is not predicted by the horizontal transmission model of Kikuchi and Araki (1979), while phase delays in the dip equator are expected in both models of wave incidence on the ionosphere. We propose that the alternative model of MHD compressional waves vertically incident on the ionosphere (Chi et al., 2001) should work simultaneously with the Earth-ionosphere waveguide model to produce Pc5 depression and phase lag at the dip equator.

Another important result is the sunrise effect observed on Pc3 ground pulsations at the stations closest to the dip equator. Its main effect on our data is to increase the $H$ component, rather than the $D$ component, as reported by studies at other longitudes. We explain this amplification by the enhancement of the zonal electric field around dawn and sought the differences with the other studies in the unique characteristics of our study area, with a strong longitudinal variation in the magnetic declination and occurrence of energetic particle precipitation due to the presence of the South Atlantic Magnetic Anomaly. It is proposed as a mechanism to give rise to the enhanced zonal electric field, based both on F-region thermospheric winds blowing eastward through the sunrise terminator (Farley et al., 1986; Kelley et al., 2014) and the mode of wave incidence on the ionosphere near the terminator.

In summary, the study presented new information about the effects of EEJ currents on the geomagnetic pulsations recorded on the ground at equatorial latitudes. The detailed characterization of the Pc5 pulsation amplification in the region around the dip equator was not previously known and was only possible by the availability of several stations operating simultaneously under the EEJ. Also noteworthy are the results on the peculiar feature of the sunrise effect in this region. A very unique combination of factors contributed to the anomalous behavior of $\mathrm{Pc} 3$ pulsations around the dawn terminator. On the other hand, interpretation is limited by the small amount of data with the stations operating simultaneously and the absence of simultaneous measurements of other ionospheric parameters during the study period which may support the proposed interpretation.

Data availability. Data for the Dst and AE indexes are publicly available at http://wdc.kugi.kyoto-u.ac.jp/dstae/index.html (last access: 6 January 2020). Data from the magnetometer array are not yet available online or at any international collaborative platform, 
but these data can be obtained by contacting the corresponding author.

Author contributions. GBDS processed the magnetic data, performed the analysis, and wrote the paper. ALP and LRA contributed to the interpretation of the data.

Competing interests. The authors declare that they have no conflict of interest.

Special issue statement. This article is part of the special issue "7th Brazilian meeting on space geophysics and aeronomy". It is a result of the Brazilian meeting on Space Geophysics and Aeronomy, Santa Maria/RS, Brazil, 5-9 November 2018.

Acknowledgements. The study was supported by a research grant from FAPESP and fellowships from CNPq. The geomagnetic experiment was designed and carried out by Tai Kitamura (Kyushu University, Japan) and Nalin B. Trivedi (INPE). We are grateful to two anonymous reviewers for their helpful comments.

Financial support. This research has been supported by the FAPESP (grant no. 92/04764-7) and the CNPq (grant nos. 304353/2013-2 and 131675/2015-0).

Review statement. This paper was edited by Marcos D. Silveira and reviewed by two anonymous referees.

\section{References}

Abdu, M. A., Batista, I. S., Carrasco, A. J., and Brum, C. G. M.: South Atlantic magnetic anomaly ionization: A review and a new focus on electrodynamic effects in the equatorial ionosphere, J. Atmos. Sol.-Terr. Phys., 67, 1643-1657, https://doi.org/10.1016/j.jastp.2005.01.014, 2005.

Aggson, T. L., Herrero, F. A., Johnson, J. A., Pfaff, R. F., Laakso, H., Maynard, N. C., and Moses, J. J.: Satellite observations of zonal electric fields near sunrise in the equatorial ionosphere, J. Atmos. Terr. Phys., 57, 19-24, https://doi.org/10.1016/00219169(93)E0013-Y, 1995.

Alperovich, L. S. and Fedorov, E. N.: Hydromagnetic waves in the magnetosphere and the ionosphere, Springer, Dordrecht, 284297, https://doi.org/10.1007/978-1-4020-6637-5, 2007.

Chi, P. J., Russell, C. T., Raeder, J., Zesta, E., Yumoto, K., Kawano, H., Kitamura, K., Petrinec, S. M., Angelopoulos, V., Le, G., and Moldwin, M. B.: Propagation of the preliminary reverse impulse of sudden commencements to low latitudes, J. Geophys. Res., 106, 18857-18864, https://doi.org/10.1029/2001JA900071, 2001.

Chi, P. J., Russell, C. T., Raeder, J., Zesta, E., Yumoto, K., Kawano, H., Kitamura, K., Petrinec, S. M., Angelopoulos, V., Le, G., and
Moldwin, M. B.: Reply to comment by T. Kikuchi and T. Araki on "Propagation of the preliminary reverse impulse of sudden commencements to low latitudes", J. Geophys. Res., 107, 1474, https://doi.org/10.1029/2002JA009369, 2002.

Elkington, S. R.: A review of ULF interactions with radiation belt electrons, in: Magnetospheric ULF Waves: Synthesis and New Directions, edited by: Takahashi, K., Chi, P. J., Denton, R. E., and Lysak, R. L., Geophys. Monogr. Ser. 169, AGU, Washington, DC, 177-193, https://doi.org/10.1029/GM169, 2006.

Engebretson, M. J., Hughes, W. J., Alford, J. L., Zesta, E., Cahill, L. J., Arnoldy, R. L., and Reeves, G. D.: Magnetometer array for cusp and cleft studies observations of the spatial extent of broadband ULF magnetic pulsations at cusp/cleft latitudes, J. Geophys. Res., 100, 19371-19386, 1995.

Farley, D. T., Bonelli, E., Fejer, B. G., and Larsen, M. F.: The prereversal enhancement of the zonal electric field in the equatorial ionosphere, J. Geophys. Res., 91, 13723-13728, https://doi.org/10.1029/JA091iA12p13723, 1986.

Hughes, W. J.: Magnetospheric ULF waves: A tutorial with a historical perspective, in: Solar Wind Sources of Magnetospheric Ultra-Low-Frequency Waves, edited by: Engebretson, M. J., Takahashi, K., and Scholer, M., Geophys. Monogr. Ser. 81, AGU, Washington, DC, 1-12, https://doi.org/10.1029/GM081, 1994.

Hughes, W. J. and Southwood, D. J.: The screening of micropulsation signals by the atmosphere and ionosphere, J. Geophys. Res., 81, 3234-3240, https://doi.org/10.1029/JA081i019p03234, 1976.

Imajo, S., Yoshikawa, A., Uozumi, T., Ohtani, S., Nakamizo, A., Demberel, S., and Shevtsov, B. M.: Solar terminator effects on middle- to low-latitude Pi2 pulsations, Earth Planet. Space, 68, 16 pp., https://doi.org/10.1186/s40623-016-0514-1, 2016.

Itonaga, M. and Kitamura, T.-I.: Effect of non-uniform ionospheric conductivity distributions on Pc3-5 magnetic pulsations - Fast wave incidence, Ann. Geophys., 11, 366-371, https://doi.org/10.5636/jgg.40.1413, 1993.

Itonaga, M., Yoshikawa, A., and Yumoto, K.: Transient response of the non-uniform equatorial ionosphere to compressional MHD waves, J. Atmos. Sol.-Terr. Phys., 60, 253-261, https://doi.org/10.1016/S1364-6826(97)00110-7, 1998.

Kanasewich, E. R.: Time Sequence Analysis in Geophysics, University of Alberta Press, Edmonton, Canada, 352 pp., 1981.

Kelley, M. C., Rodrigues, F. S., Pfaff, R. F., and Klenzing, J.: Observations of the generation of eastward equatorial electric fields near dawn, Ann. Geophys., 32, 1169-1175, https://doi.org/10.5194/angeo-32-1169-2014, 2014.

Kessel, R. L.: Solar wind excitation of Pc5 fluctuations in the magnetosphere and on the ground, J. Geophys. Res., 113, A04202, https://doi.org/10.1029/2007JA012255, 2008.

Kikuchi, T. and Araki, T.: Horizontal transmission of the polar electric field to the equator, J. Atmos. Terr. Phys., 41, 927-936, https://doi.org/10.1016/0021-9169(79)90094-1, 1979.

Kikuchi, T. and Araki, T.: Comment on "Propagation of the preliminary reverse impulse of sudden commencements to low latitudes", by P. J. Chi et al., J. Geophys. Res., 107, 1473 , https://doi.org/10.1029/2001JA009220, 2002.

Le Mouel, J. L., Shebalin, P., and Chulliat, A.: The field of the equatorial electroject from CHAMP data, Ann. Geophys., 24, 515527, https://doi.org/10.5194/angeo-24-515-2006, 2006. 
Matsuoka, H., Takahashi, K., Kokubun, S., Yumoto, K., Yamamoto, T., Solovyev, S. I., and Vershinin, E. F.: Phase and amplitude structure of Pc 3 magnetic pulsations as determined from multipoint observations, J. Geophys. Res., 102, 2391-2404, https://doi.org/10.1029/96JA02918, 1997.

Matsushita, S. and Maeda, H.: On the geomagnetic solar quiet daily variation field during the IGY, J. Geophys. Res., 70, 2535-2558, https://doi.org/10.1029/JZ07i011p02535, 1965.

McPherron, R. L.: Magnetic pulsations: their sources and relation to solar wind and geomagnetic activity, Surv. Geophys., 26, 545592, https://doi.org/10.1007/s10712-005-1758-7, 2005.

Padilha, A. L., Alves, M. V., Trivedi, N. B., Kitamura, T.-I., and Shinohara, M.: Bursty Pi1 activity at the South American equatorial zone during the 29 October 1994 magnetic storm, Geophys. Res. Lett., 30, 4 pp., https://doi.org/10.1029/2003GL017999, 2003.

Padilha, A. L., Alves, L. R., Silva, G. B. D., and Espinosa, K. V.: Effect of a huge crustal conductivity anomaly on the H-component of geomagnetic variations recorded in central South America, Earth Planet. Space, 69, 10 pp., https://doi.org/10.1186/s40623017-0644-0, 2017.

Paulikas, G. A.: Precipitation of particles at low and middle latitudes, Rev. Geophys. Space Phys., 13, 709-734, https://doi.org/10.1029/RG013i005p00709, 1975.

Rastogi, R. G., Chandra, H., James, M. E., Kitamura, T., and Yumoto, K.: Characteristics of the equatorial electrojet current in the central region of South America, Earth Planet. Space, 60, 623-632, https://doi.org/10.1186/BF03353126, 2008.

Reddy, C. A., Ravindran, S., Viswanathan, K. S., Krishna Murthy, B. V., Rao, D. R. K., and Araki, T.: Observations of Pc5 micropulsation-related electric field oscillations in equatorial ionosphere, Ann. Geophys., 12, 565-573, https://doi.org/10.1007/s00585-994-0565-7, 1994.

Roy, M. and Rao, D. R. K.: Frequency dependence of equatorial electrojet effect on geomagnetic micropulsations, Earth Planet. Space, 50, 847-851, https://doi.org/10.1186/BF03352178, 1998.

Russell, C. T., Luhmann, J. G., Odera, T. J., and Stuart, W. F.: The rate of occurrence of dayside Pc3,4 pulsations - The L-value dependence of the IMF cone angle effect, Geophys. Res. Lett., 10, 663-666, https://doi.org/10.1029/GL010i008p00663, 1983.

Saka, O. and Alperovich, L.: Sunrise effect on dayside Pc pulsations at the dip equator, J. Geophys. Res., 98, 13779-13786, https://doi.org/10.1029/93JA00730, 1993.

Saka, O., Itonaga, M., and Kitamura, T.: Ionospheric control of polarization of low-latitude geomagnetic micropulsations at sunrise, J. Atmos. Terr. Phys., 44, 703-712, https://doi.org/10.1016/0021-9169(82)90132-5, 1982.

Saka, O., Shinohara, M., Akaki, H., Inoue, H., Uozumi, T., and Kitamura, T.: A time source of data aquisition system designed for phase propagation study of magnetic pulsations, J. Geomagn. Geoelectr., 48, 1321-1326, https://doi.org/10.5636/jgg.48.1321, 1996.

Sarma, S. V. S. and Sastry, T. S.: On the Equatorial electrojet influence on geomagnetic pulsation amplitudes, J. Atmos. Terr. Phys., 57, 749-754, https://doi.org/10.1016/00219169(94)00053-Q, 1995.

Shinohara, M., Yumoto, K., Yoshikawa, A., Saka, 0., Solovyev, S. I., Vershinin, E. F., Trivedi, N. B., Da Costa, J. M., and The $210^{\circ}$ MM Magnetic Observation Group: Wave characteristics of daytime and nighttime Pi 2 pulsations at the equa- torial and low latitudes, Geophys. Res. Lett., 24, 2279-2282, https://doi.org/10.1029/97GL02146, 1997.

Shinohara, M., Yumoto, K., Hosen, N., Yoshikawa, A., Tachihara, H., Saka, O., Kitamura, T.-I., Tivedi, N. B., Da Costa, J. M., and Schuch, N. J.: Wave characteristics of geomagnetic pulsations across the dip equator, J. Geophys. Res., 103, 11745-11754, https://doi.org/10.1029/97JA03067, 1998.

Tachihara, H., Shinohara, M., Shimoizumi, M., Saka, O., and Kitamura, T.: Magnetometer system for studies of the Equatorial Electrojet and micropulsations in equatorial regions, J. Geomagn. Geoelectr., 48, 1311-1319, https://doi.org/10.5636/jgg.48.1311, 1996.

Takla, E. M., Yumoto, K., Cardinal, M. G., Abe, S., Fujimoto, A., Ikeda, A., Tokunaga, T., Yamazaki, Y., Uo-Zumi, T., Mahrous, A., Ghamry, E., Mengistu, G., Afullo, T., Macamo, A., Joao, L., Mweene, H., Mwiinga, N., Uiso, C., Baki, P., Kianji, G., Badi, K., Sutcliffe, P., and Palangio, P.: A study of latitudinal dependence of Pc3-4 amplitudes at $96^{\circ}$ magnetic meridian stations in Africa, Sun Geosph., 6, 67-72, 2011.

Tamao, T.: The structure of three-dimensional hydromagnetic waves in a uniform cold plasma, J. Geomagn. Geoelectr., 16, 89114, https://doi.org/10.5636/jgg.16.89, 1964.

Tanaka, Y.-M., Yumoto, K., Yoshikawa, A., Shinohara, M., Kawano, H., and Kitamura, T.-I.: Longitudinal structure of Pc3 pulsations on the ground near the magnetic equator, J. Geophys. Res., 109, 10 pp., https://doi.org/10.1029/2003JA009903, 2004.

Tanaka, Y.-M., Yumoto, K., Yoshikawa, A., Itonaga, M., Shinohara, M., Takasaki, S., and Fraser, B. J.: Horizontal amplitude and phase structure of low-latitude Pc 3 pulsations around the dawn terminator, J. Geophys. Res., 112, 10 pp., https://doi.org/10.1029/2007JA012585, 2007.

Trivedi, N. B., Arora, B. R., Padilha, A. L., Da Costa, J. M., Dutra, S. L. G., Chamalaun, F. H., and Rigoti, A.: Global Pc5 geomagnetic pulsations of March 24, 1991, as observed along the American sector, Geophys. Res. Lett., 24, 1683-1686, https://doi.org/10.1029/97GL00215, 1997.

Tsunomura, S. and Araki, T.: Numerical analysis of equatorial enhancement of geomagnetic sudden commencement, Planet. Space Sci., 32, 599-604, https://doi.org/10.1016/00320633(84)90109-0, 1984.

WDC for Geomag. KYOTO: Data for the Dst and AE indexes, available at: http://wdc.kugi.kyoto-u.ac.jp/dstae/index.html, last access: 6 January 2020.

Yizengaw, E., Zesta, E., Biouele, C. M., Moldwin, M. B., Boudouridis, A., Damtie, B., Mebrahtu, A., Anad, F., Pfaff, R. F., and Hartinger, M.: Observations of ULF wave related equatorial electrojet and density fluctuations, J. Atmos. Sol.-Terr. Phys., 103, 157-168, https://doi.org/10.1016/j.jastp.2013.03.015, 2013.

Yumoto, K.: Generation and propagation mechanisms of lowlatitude magnetic pulsations - A review, J. Geophys., 60, 79-105, 1986.

Yumoto, K. and Saito, T.: Relation of compressional HM waves at GOES 2 to low-latitude Pc3 magnetic pulsations, J. Geophys. Res., 88, 10041-10052, https://doi.org/10.1029/JA088iA12p10041, 1983.

Yumoto, K., Saito, T., Akasofu, S. I., Tsurutani, B. T., and Smith, E. J.: Propagation mechanism of daytime Pc34 pulsations observed at synchronous orbit and multiple 
ground-based stations, J. Geophys. Res., 90, 6439-6450, https://doi.org/10.1029/JA090iA07p06439, 1985.

Zanandrea, A., Da Costa, J. M., Dutra, S. L. G., Trivedi, N. B., Kitamura, T., Yumoto, K., Tachihara, H., Shinohara, M., and Saotome, O.: Pc3-4 geomagnetic pulsations at very low latitude in Brazil, Planet. Space Sci., 52, 1209-1215, https://doi.org/10.1016/j.pss.2004.08.001, 2004.
Zhang, R., Liu, L., Chen, Y., and Le, H.: The dawn enhancement of the equatorial ionospheric vertical plasma drift, J. Geophys. Res., 120, 10688-10697, https://doi.org/10.1002/2015JA021972, 2015.

Ziesolleck, C. W. S. and Chamalaun, F. H.: A two-dimensional array study of low-latitude Pc 5 geomagnetic pulsations, J. Geophys. Res., 98, 13703-13713, https://doi.org/10.1029/93JA00637, 1993. 